\title{
ASSESSMENT OF SOME MECHANICAL PROPERTIES AND MICROSTRUCTURE OF PARTICULATE PERIWINKLE SHELL-ALUMINIUM 6063 METAL MATRIX COMPOSITE (PPS-ALMMC) PRODUCED BY TWO-STEP CASTING
}

\author{
R. Umunakwe ${ }^{1,}{ }^{*}$, D. J. Olaleye ${ }^{2}$, A. Oyetunji ${ }^{3}$, O. C. Okoye ${ }^{4}$ and I. J. Umunakwe ${ }^{5}$

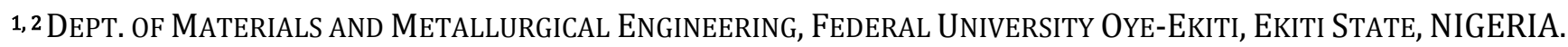 \\ 3 Dept. of MetalluRgical and Materials EnGr., Fed. University of TeChNology AKure, Ondo State, Nigeria. \\ ${ }^{4}$ Department of Mechanical EngineERING, FEdERAl University OYE-EKiti, EKITI STate, NIGERIA. \\ 5DEPARTMENT OF CHEMISTRY, FEDERAL UNIVERSITY OF TECHNOLOGY OWERRI, IMO STATE, NIGERIA. \\ E-mail addresses:1 reginald.umunakwe@fuoye.edu.ng, 2 oladex55@gmail.com, \\ 3akinlabioyetunji@yahoo.com, ${ }^{4}$ obinna.okoye@fuoye.edu.ng, ${ }^{5}$ sweetifyforlord@gmail.com
}

\begin{abstract}
This work investigates some mechanical properties and microstructures of PPS-AIMMC and compares the properties of

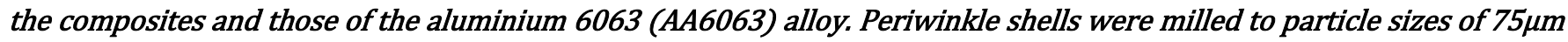
and 150 $\mu \mathrm{m}$ and used to produce PPS-AIMMC at 1,5,10 and 15wt\% filler loadings using two-step casting technique. The mechanical properties and microstructures of the composite materials were compared with those of the AA6063 alloy. It was observed that the filler distributes uniformly in the matrix due to the two-step casting technique. Improved strength, ductility, hardness and modulus were obtained when the filler was used to reinforce the alloy. However, using a filler of bigger particle size resulted to reduced tensile strength, ductility and toughness of composites.
\end{abstract}

Key words: Composites, Periwinkle shell, Aluminum, Mechanical properties, Microstructure

\section{INTRODUCTION}

Researchers have shown interests in the development of aluminum metal matrix composite (Al-MMCs) because of their potential applications in industries such as aerospace, automotive, thermal management, electrical and electronic as well as sports. Al-MMCs are engineered materials made by incorporating non-metallic reinforcement(s) into aluminium or its alloy so as to tailor the properties such as strength, hardness, stiffness, electrical and thermal conductivity as well as other properties of the material. Al-MMCs offer high strength to weight ratio and high stiffness to weight ratio [1]. In the composite, the good properties of the metal such as light weight, high ductility, electrical and thermal conductivities are combined with the properties of the reinforcement such as low coefficient of thermal expansion, high stiffness, and strength and abrasion resistance to produce material with desired properties. The reinforcement could be in the form of continuous and discontinuous fibres, whiskers or particulate [2]. The applications of Al-MMCs are limited by high cost and hence the search for cheap agricultural materials as reinforcements to enhance their applications [3]. Particulate Al-MMCs (PAl-MMcs) are less expensive compared to continuous fibre reinforced Al-MMCs
(CFRAL-MMCs) and are usually produced by either the solid state (powder metallurgy processing) or liquid state (stir casting, infiltration and in-situ) processes [2]. The particulate ceramics materials used to reinforce aluminium are usually carbides, oxides and borides such as $\mathrm{SiC}, \mathrm{Al}_{2} \mathrm{O}_{3}, \mathrm{TiB}, \mathrm{TiC}$, etc. [4]. The properties of the material are affected by factors such as the type of reinforcement, the method of production, the volume or mass fraction of reinforcement, the particle size of the reinforcement, the shape and distribution of the reinforcement in the matrix. For example, the impact strength and hardness of particulate $\mathrm{Al}-\mathrm{SiC} \mathrm{MMC}$ have been reported to increase with increasing weight fraction of reinforcement and at $25 \mathrm{wt} \%$ of the reinforcement; there was over $100 \%$ increase in strength and about $90 \%$ improvement in the hardness of the composite over those of the pure aluminium [5]. The method of stirring also affected the dispersion of the reinforcement in the matrix [5]. Also, the density, strength and hardness of Al6061-SiC and Al7075- $\mathrm{Al}_{2} \mathrm{O}_{3}$ were compared at 2,4 and $6 \mathrm{wt} \%$ addition of reinforcements and it was reported that the experimental densities of the composites were similar to those of the theoretical densities, however, the addition of $\mathrm{Al}_{2} \mathrm{O}_{3}$ into the $\mathrm{Al}$ matrix resulted to improved strength,

\footnotetext{
* Corresponding author, tel: + 234-805-123- 7368
} 
hardness and density slightly higher than the improvement obtained with $\mathrm{SiC}$ addition; the addition of harder reinforcements also improved the wear resistance of the composites over that of the unreinforced $\mathrm{Al}$ alloy [6]. Low density, low coefficient of thermal expansion, good mechanical strength and hardness, as well as good thermal and electrical conductivities are some of the properties that make AlMMCs functional electronic packaging and thermal management materials especially for weight sensitive applications over conventional copper tungsten (CuW) and copper molybdenum alloys [1,7]. Some works have recently been reported on the utilization of agricultural wastes as filler for Al-MMCs[3, 8-10]. Agricultural wastes are cheap compared to carbide, oxide and boride fillers. They constitute environmental problems, hence, the need to find useful applications for them. Rice husk ash $(2-3 \mu \mathrm{m})$ has been used to reinforce AA6061 aluminium alloy and it was reported that the reinforcement distributes uniformly in the matrix and enhanced the tensile strength and hardness with increase in mass fraction of the reinforcement up $8 \%$ over the unreinforced alloy [3]. Particulate coconut shell was used to reinforce recycled aluminium cans to improve the tensile strength and wear resistance [8]. The use of rice husk ash (RHA) as the reinforcement for aluminium(AlSi10Mg)-RHA composite was investigated; it was reported that there is filler distribution in the matrix, tensile strength, compressive strength and hardness increased with the increase in weight fraction of the reinforcement and the properties are better at smaller particle sizes [9].Furthermore, the properties of Al-7\%Si-Rice Husk Ash and Al-7\%Si-Bagasse Ash composites were compared and rice husk ash offered better reinforcing properties than bagasse ash [10]. Also, Fly ash has also been used to produce fly ash reinforced aluminium alloy (Al6061) composites [11].

Periwinkle (Turritella communis) is a type of edible sea snail which is dark, oval in shape with hard shell. Periwinkles are abundant on rocky shores in hinterlands in the South-South of Nigeria which include Cross-River, Rivers, Akwa-Ibom and Bayelsa. They are sold in various markets across the country. After consumption, the shells are discarded and add to solid wastes in the metropolis. Some researchers have investigated the use of periwinkle shell as reinforcement for cashew nut shell liquid [12-13], polyester [14-15] and phenolic resin [1617]. In all these, particulate periwinkle shell was reported to improve the tensile strength, compressive strength, wear resistance and also lowers the density. Higher mechanical properties were achieved with smaller particle sizes.

In this work, we evaluated the effect of particle size and weight fraction of particulate periwinkle shell filler on the mechanical properties and microstructures of PPSAlMMC.

\section{MATERIALS AND METHODS}

\subsection{Materials}

The major materials required for this work were aluminium 6063 alloy (AA6063) and periwinkle shells. The alloy with chemical composition shown in Table 1 was purchased from the Nigerian Aluminium Extrusion Limited (NIGALEX), Lagos, Nigeria. Periwinkle shells were sourced from the local market at Otueke, Bayelsa State, Nigeria.

\subsection{Materials preparation \\ 2.2.1. Production of PPS;}

Periwinkle shells were, washed, boiled in water at $100^{\circ} \mathrm{C}$ for 40 minutes, allowed to cool, thoroughly washed to remove sand particles and dirt and thereafter dried under the sun for two days and heated in an oven at $110^{\circ} \mathrm{C}$ for thirty minute to remove all moisture. The shells were crushed with hammer mill, pulverized with a ball mill and sieved to $75 \mu \mathrm{m}$ and $150 \mu \mathrm{m}$ particle sizes using BS standard sieves.

\subsubsection{Stir Casting;}

Two-step casting as described by [18] was used to produce the composite materials. The quantities of AA6063 and PPS required to produce composites having $1,5,10$ and 15 weight percent of the PPS were weighed out using digital electric balance (Model XYC 3000, sensitivity $0.01 \mathrm{~g}$ ) based on charge calculations. The charge compositions of the cast composite materials and the control specimen are shown in Table 2.

The aluminium ingot was charged into a gas-fired crucible furnace and heated to $730^{\circ} \mathrm{C} \pm 30^{\circ} \mathrm{C}$ which is above the liquidus temperature of the alloy and the liquid was allowed to cool in a furnace to a semi-solid state of temperature about $600^{\circ} \mathrm{C}$.

Table 1: Composition of the aluminium ingot

\begin{tabular}{lllllllll}
\hline Element & $\mathrm{Al}$ & $\mathrm{Si}$ & $\mathrm{Fe}$ & $\mathrm{Cu}$ & $\mathrm{Mn}$ & $\mathrm{Mg}$ & $\mathrm{Zn}$ & $\mathrm{Cr}$ \\
\hline Average content & 98.18 & 0.5953 & 0.4635 & 0.0117 & 0.0244 & 0.3459 & $<0.002$ & 0.0107 \\
Element & $\mathrm{Ni}$ & $\mathrm{Ti}$ & $\mathrm{Sr}$ & $\mathrm{Zr}$ & $\mathrm{V}$ & $\mathrm{Ca}$ & $\mathrm{Be}$ & $<0.000$ \\
Average content & 0.0347 & 0.0566 & $<0.000$ & 0.0772 & 0.0114 & $>0.070$ & $<$ \\
\hline
\end{tabular}


Table 2: Charge compositions of the composite materials

\begin{tabular}{llllllll}
\hline Specimen & $\begin{array}{l}\text { Particle size } \\
\text { PPS }(\mu \mathrm{m})\end{array}$ & $\begin{array}{l}\text { Weight percent of } \\
\text { PPS }(\text { wt\%) }\end{array}$ & $\begin{array}{l}\text { Weight percent } \\
\text { AA6063 matrix }(w t \%)\end{array}$ & of $\begin{array}{l}\text { Weight } \\
\text { of PPS }\end{array}$ & $\begin{array}{l}\text { Weight }(\mathrm{g}) \\
\text { AA6063 matrix }\end{array}$ & of \\
\hline 1 & Nil (control) & 00 & 100 & & 00 & 250.0 \\
2 & 75 & 1 & 99 & & 2.5 & 247.5 \\
3 & 75 & 5 & 95 & & 12.5 & 237.5 \\
4 & 75 & 10 & 90 & & 25.0 & 225.0 \\
5 & 75 & 15 & 85 & & 37.5 & 212.5 \\
6 & 150 & 1 & 99 & & 2.5 & 247.5 \\
7 & 150 & 5 & 95 & & 12.5 & 237.5 \\
8 & 150 & 10 & 90 & & 25.0 & 225.0 \\
9 & 150 & 15 & 85 & 37.5 & 212.5 & \\
\hline
\end{tabular}

Table 3: Elemental composition of PPS

\begin{tabular}{lllllllllll}
\hline Element & $\mathrm{Ca}$ & $\mathrm{Fe}$ & $\mathrm{Si}$ & $\mathrm{Mo}$ & $\mathrm{Al}$ & $\mathrm{P}$ & $\mathrm{S}$ & $\mathrm{Sn}$ & $\mathrm{Sb}$ & Others Elements \\
\hline Content & 70.3350 & 0.5066 & 0.0724 & 0.2372 & 0.1938 & 0.2746 & 0.3987 & 0.4561 & 0.4511 & 27.0745 \\
\hline
\end{tabular}

The calculated PPS was added at this temperature and the semi-solid mixture was stirred manually with a spindle for five minutes. The composite slurry was reheated to $730^{\circ} \mathrm{C}$ and stirred vigorously for five minutes and the molten composite was cast in metallic die. Unreinforced AA6063 was also cast as the control specimen.

\subsection{Characterizations}

\subsubsection{Chemical Analysis of PPS}

$\mathrm{X}$-ray Fluoresce Spectrometer was used to determine the elemental composition of the PPS. The system detects elements between sodium ( $\mathrm{Na}, \mathrm{Z}=11)$ and uranium $(\mathrm{U}, \mathrm{Z}$ $=92$ ). PPS is found to contain majorly calcium as shown in Table 3.

\subsubsection{Tensile Testing;}

Uniaxial tensile test was performed on each specimen at room temperature using Instron Universal Testing Machine at a cross-head speed of $10 \mathrm{~mm} / \mathrm{s}$. The tensile specimens were machined and tested in accordance with ASTM E8M-91 [19] with the gauge length of $40 \mathrm{~mm}$ and gauge diameter of $5 \mathrm{~mm}$. For each specimen, three repeated tests were carried out to guarantee reliability. The tensile properties reported are tensile strength, modulus of elasticity, percentage elongation and energy at break.

\subsubsection{Hardness Testing;}

The hardness of the aluminium alloy and composites was determined with Vicker Hardness Tester (LECO AT 700 Microhardness Tester). The dimension of each specimen for hardness testing was $25 \times 20$ mmand each specimen was grinded and polished to obtain a flat smooth surface. During the testing, a load of $980.7 \mathrm{mNw}$ as applied for $10 \mathrm{~s}$ on the specimen through square based pyramid indenter and the hardness readings taken in a standard manner.
The readings were taken in three different points at the surface of the hardness specimen and the average computed as the hardness of the specimen.

\subsubsection{Metallography;}

Software driven optical metallurgical microscope was used to study the microstructure of the alloy as well as the composites. Prior to viewing of specimens with optical microscope, emery papers of grit sizes ranging from $500 \mu \mathrm{m}-1500 \mu \mathrm{m}$ were usedto polish the surfaces of the specimens. Thereafter, fine polishing was performed using a suspension of polycrystalline diamond of particle sizes ranging from $10 \mu \mathrm{m}-0.5 \mu \mathrm{m}$ with ethanol solvent. Each specimen was etched with $1 \mathrm{HNO}_{3}: 1 \mathrm{HCl}$ solution [18] prior to viewing with the optical microscope for micro structural study.

\section{RESULTS AND DISCUSSION}

\subsection{Microstructure:}

The optical micrographs of the AA6063 alloy and those of the composites are shown in Figures 1-9.Figure 1 shows the micrograph of the unreinforced alloy. It can be seen that the grains are coarse compared to Figures 2-5 with finer grains when PPS of $75 \mu \mathrm{m}$ was used as the filer. PPS of smaller particle size with higher surface area refined the grains of the alloy. The finer grained composites exhibited higher strength, ductility and toughness as shown in Figures 10,12 and 13. It was also observed that PPS dispersed in AA6063 alloy as seen from the homogeneity of the microstructures. Figures 6-7 respectively show the micrographs of the composites reinforced with 1 and $5 \mathrm{wt} \%$ PPS of $150 \mu \mathrm{m}$ particle size. Due to smaller weight fractions and small surface area of bigger particle sized PPS, the matrix did not effectively interact with the grain refining ingredient in PPS and this resulted to coarse grains in the microstructures as shown in Figures 6-7. 


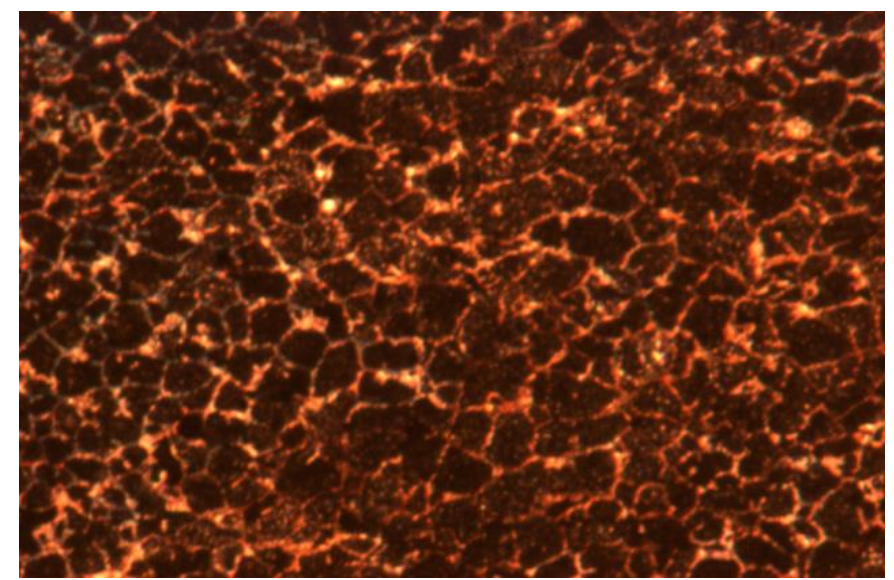

Figure 1: Optical micrograph of specimen 1 ( $(50)$

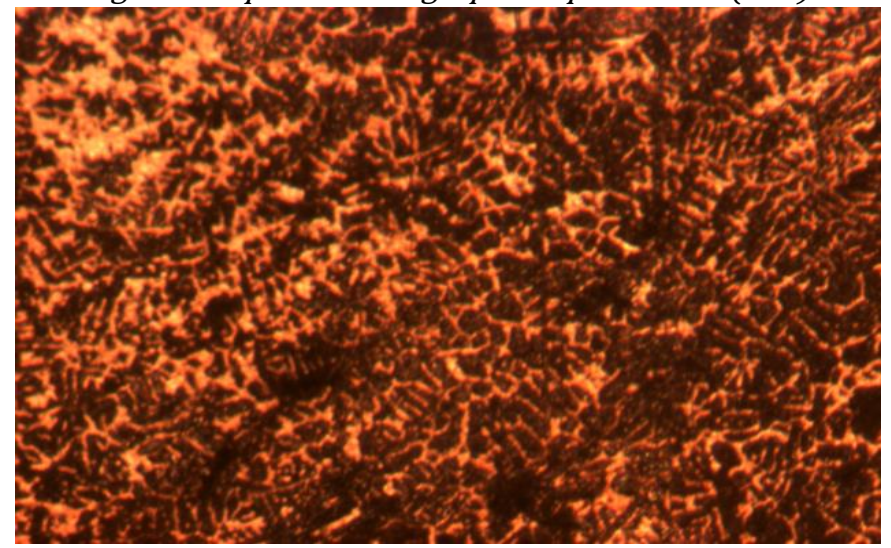

Figure 3: Optical micrograph of specimen 3 (x50)

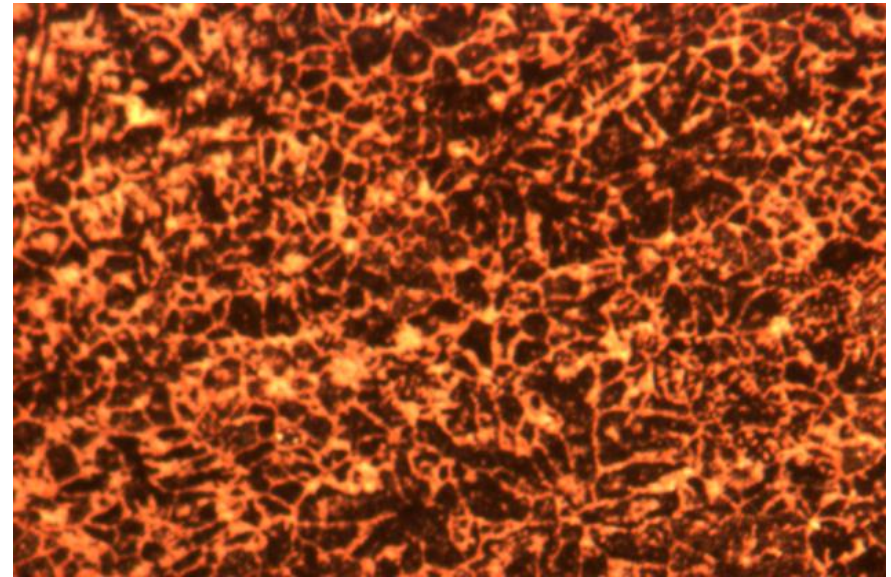

Figure 5: Optical micrograph of specimen 5 (x50)

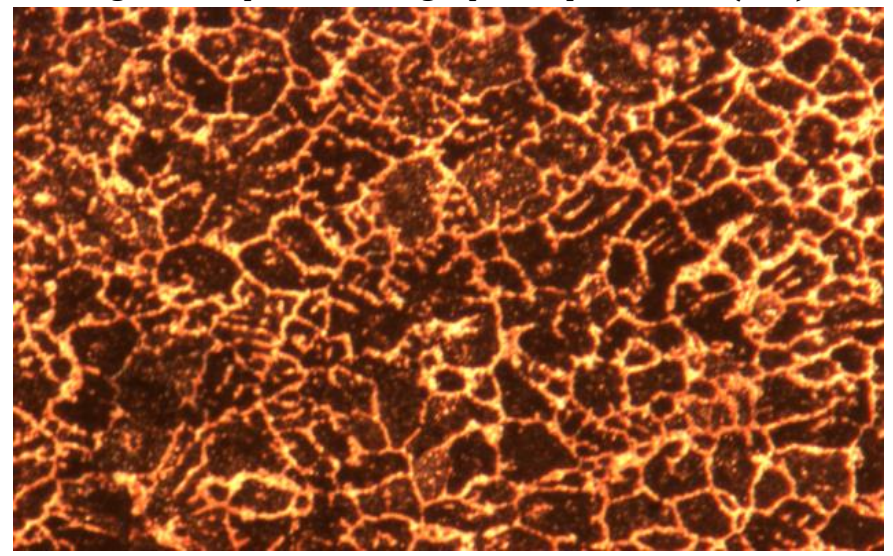

Figure 7: Optical micrograph of specimen 7 (x50)

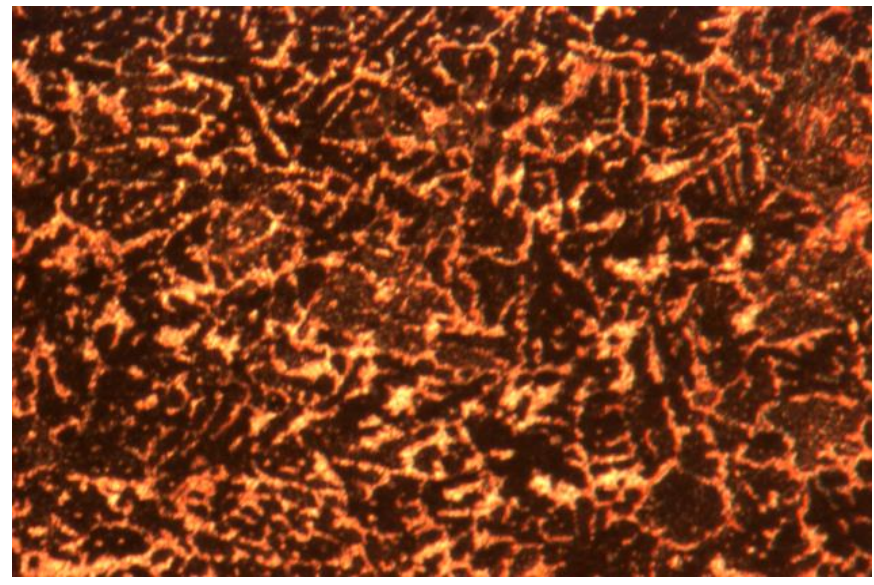

Figure 2: Optical micrograph of specimen 2 (x50)

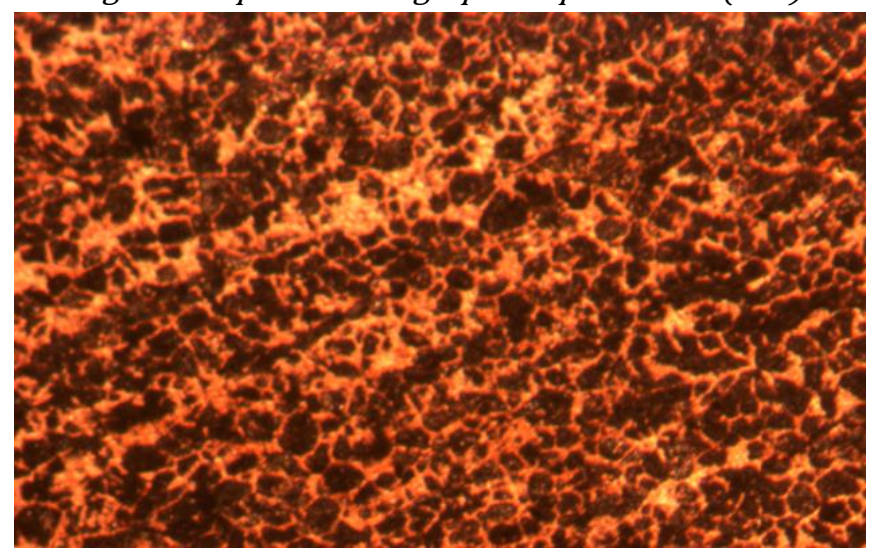

Figure 4: Optical micrograph of specimen 4 (x50)

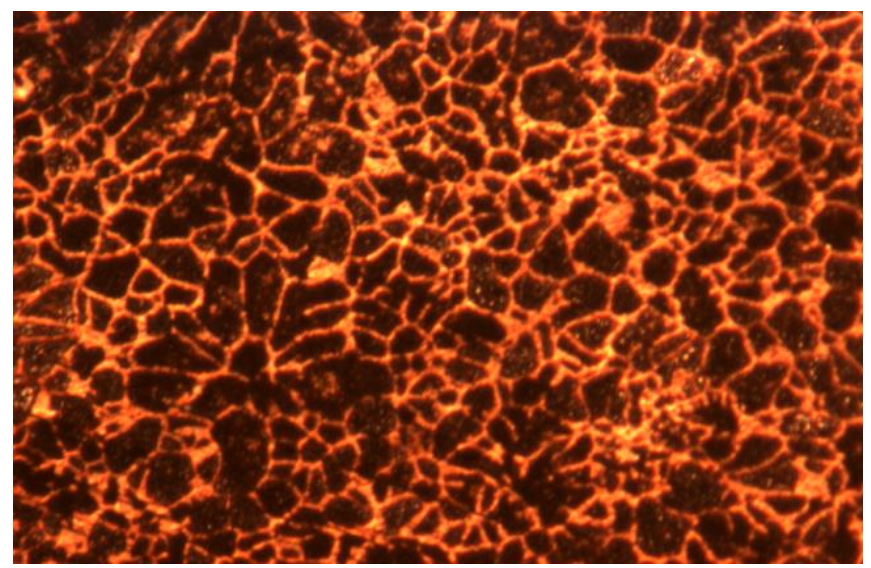

Figure 6: Optical micrograph of specimen 6 (x50)

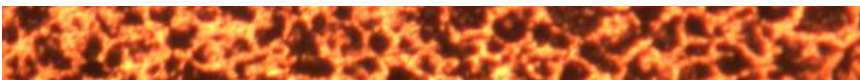

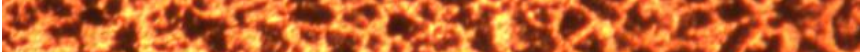

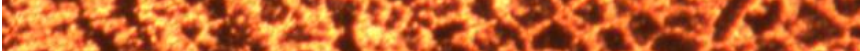

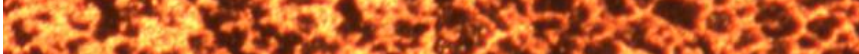

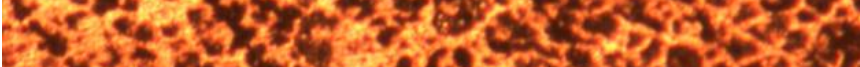

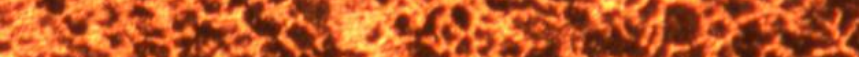

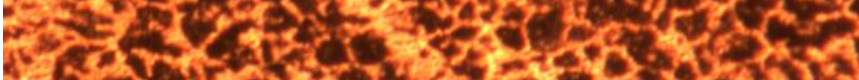

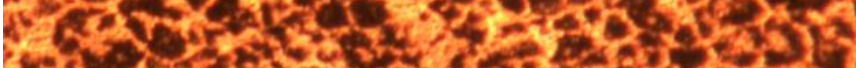

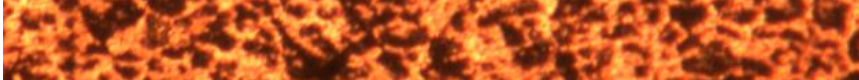

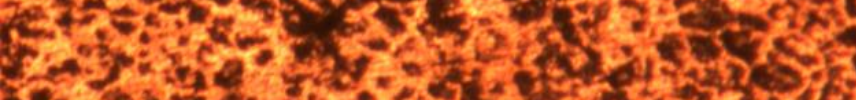

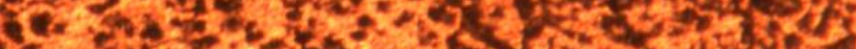

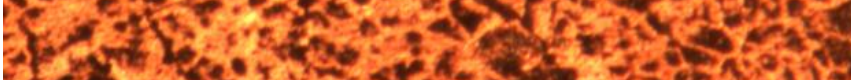

Figure 8: Optical micrograph of specimen 8 (x50) 


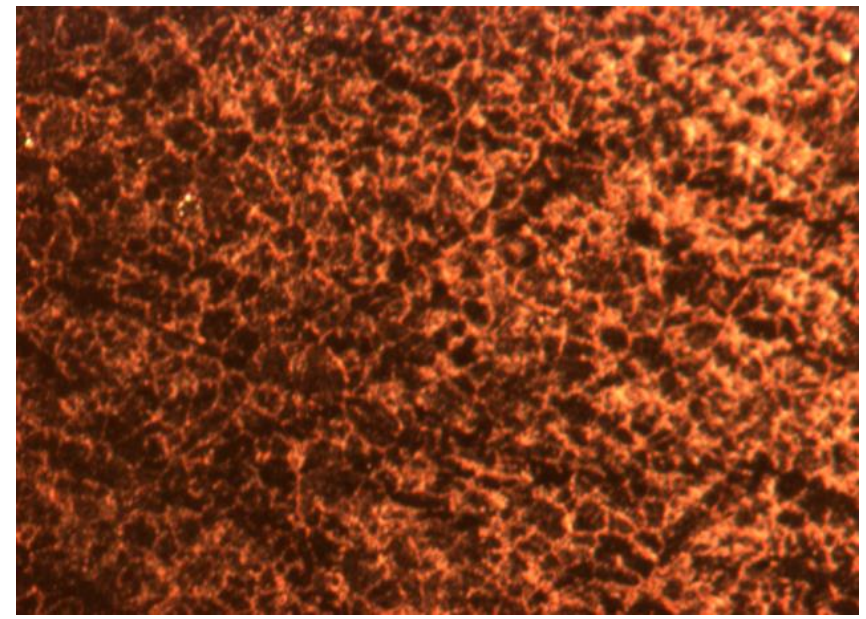

Figure 9: Optical micrograph of specimen 9 ( $x 50)$

However, when the $150 \mu \mathrm{m}$ particle sized PPS was used at $10-15 w t \%$ filler loading in the AA6063 alloy, the grains of the microstructures were refined as shown in Figures 8 and 9 due to higher weight fraction of PPS, but the dispersion of the filler in matrix was poor as the PPS was seen agglomerated in certain parts of the micrograph.

\subsection{Tensile Properties:}

The tensile strength, elastic modulus, percentage elongation of the alloy and PPS-AIMMCs are shown in Figures 10-14. When PPS of bigger particle size was used as the filler, the increase in elastic modulus is more significant and it increases gradually up to $10 \mathrm{wt} \%$ filler loading before it started depreciating as shown in Figure 11. With PPS of smaller particle size in AA6063 alloy, the composites exhibited lower elastic moduli, the elastic modulus increased gradually with increase in filler weight percent, and at $15 \mathrm{wt} \%$ filler, higher value of elastic modulus of composite compared to the unreinforced alloy was obtained as shown in Figure 11. The lower moduli observed in composites with smaller particle size PPS was due the higher ductility exhibited by the composites as shown in Figure 12. At small particle size, improvement in tensile strength of the composite materials compared to the alloy up to $10 \mathrm{wt} \%$ of PPS in the alloy was observed as shown in Figure 10. No further improvement in strength was observed after $10 \mathrm{wt} \%$ filler loading was observed. Composites reinforced with PPS of bigger particle size exhibited reduced tensile strength above $5 \mathrm{wt} \%$ filler loading as shown in Figure 10. The introduction of PPS in AA6063 alloy was also observed to improve ductility and toughness at $75 \mu \mathrm{m}$ particle size of the filler compared to the values obtained at $150 \mu \mathrm{m}$ particle size as shown in Figures 12 and 13. From the results, it can deduced that PPS has strengthening capacity as a filler in AA6063 alloy, however, the mechanical properties that could be obtained depends on the particle size of the filler used to reinforce the matrix. Also, due to the ability of PPS to refine the grains of the alloy as shown in the micrographs (Figures 2-5), improved ductility, strength and toughness were observed in the composites reinforced with smaller particle size PPS over those of the alloy as shown in Figure 10, 12 and 13 in line with Hall Petch Equation [20].However, at bigger particle size of the filler, due to small surface area of filler, poor wettability and poor filler dispersion at higher weight fraction, the porosity of the composite increases which gives rise to lower strength at high percentage of the filler in the matrix.

\subsection{Hardness:}

The hardness of AA6063 alloy and PPS-AIMMC are shown in Figure 14. In the composite with $75 \mu \mathrm{m}$ PPS filler, there was a decrease in hardness at $1 \mathrm{wt} \%$ filler addition followed by continuous increase in hardness at $5,10 \mathrm{wt} \%$ and at $15 \mathrm{wt} \%$ filler in composite, the composite exhibited about $7 \%$ improvement in hardness over that of the alloy. This follows the same trend in Modulus of Elasticity as shown in Figure 11.However, at $150 \mu \mathrm{m}$ PPS particle size, maximum hardness was achieved at $1 \mathrm{wt}$ filler loading followed by $5 \mathrm{wt} \%$ filler content and thereafter the hardness becomes lower compared to the alloy. The decrease in hardness at higher filler loading is due to poor filler dispersion in the matrix.PPS has the potential to improve the hardness at low $w t \%$ with bigger particle size filler while with smaller particle size filler, improved hardness is achieved at higher wt $\%$ filler loading.

The improvement of mechanical properties of PPS as filler in AA6063 alloy at smaller particle sizes follows the trend of earlier reports where PPS was used as filler in cashew nut shell liquid [12-13], polyester resin [14-15] and phenolic resin [16-17]. Also, the improved mechanical properties obtained with PPS filler in AA6063 at smaller particle size follow the reported trend when other agricultural wastes such as coconut shell [8] and rice husk ash [3] were used as fillers in aluminium alloys. This work however evaluated the suitability of PPS as filler in aluminum alloy which was not reported. 


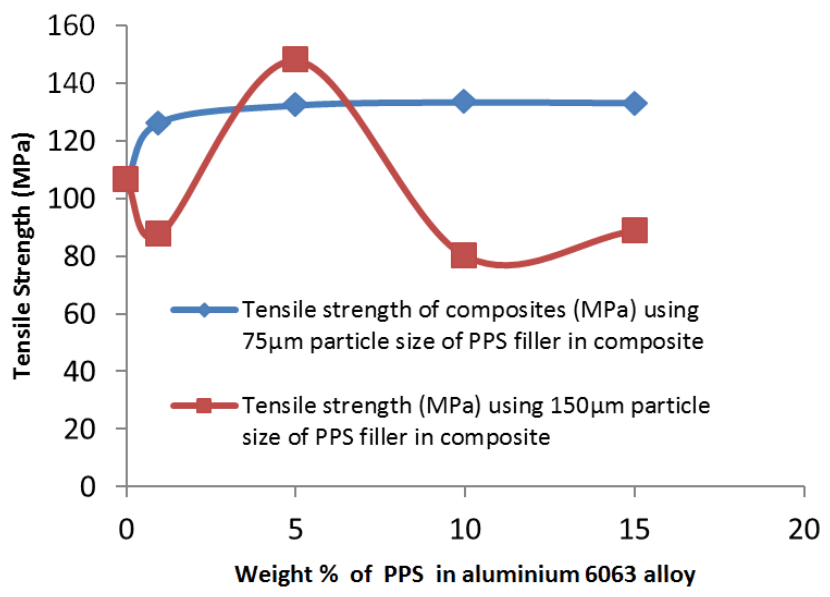

Figure 10: Tensile strengths of AA6063 alloy and PPSAIMMCS

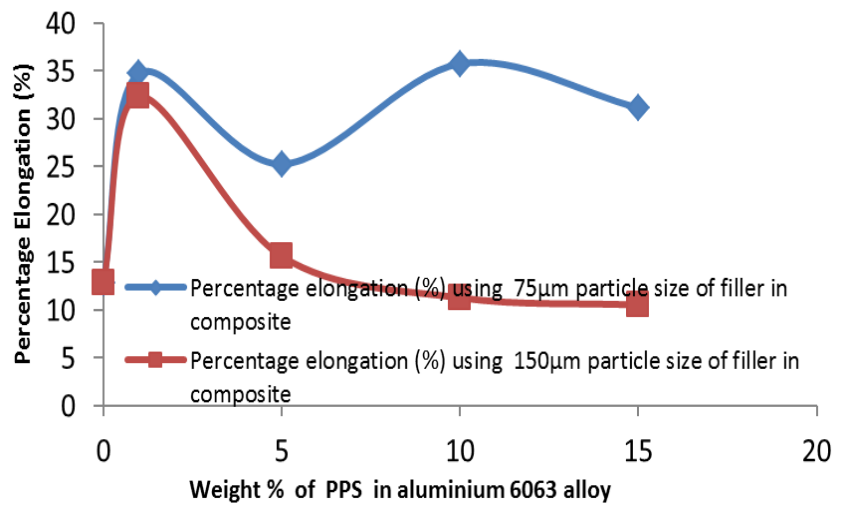

Figure 12: Percentage elongations of AA6063 alloy and PPS-AIMMCS

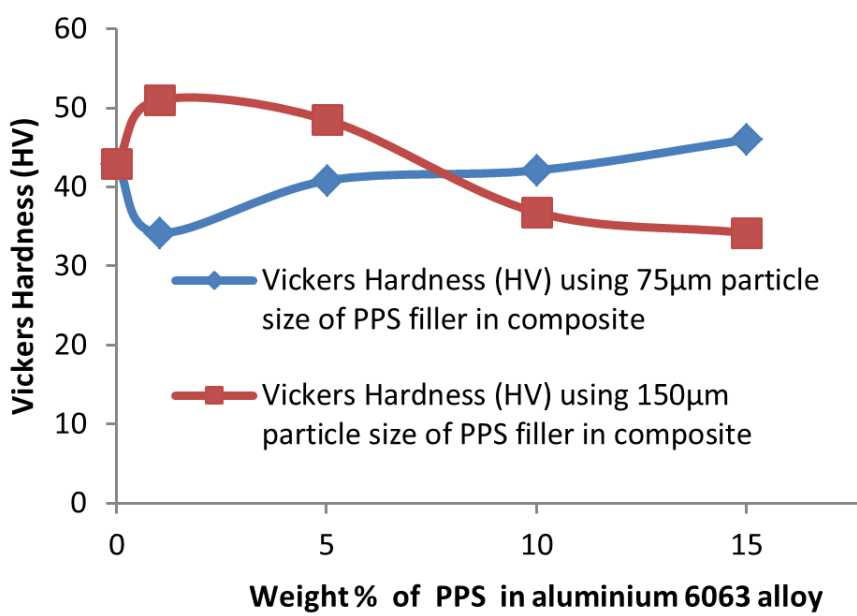

Figure 14: Vickers hardness of AA6063 and PPS-AIMMC composites

\section{CONCLUSIONS:}

From the results, the following can be concluded;

i. PPS distributes uniformly in AA6063 alloy and refines the grains from coarse grains to fine grains at smaller particle size.

ii. Due to the ability of PPS to refine the grains of AA6063 alloy, the addition of PPS in the alloy improves the strength, elastic modulus, ductility and hardness of the composites. The properties

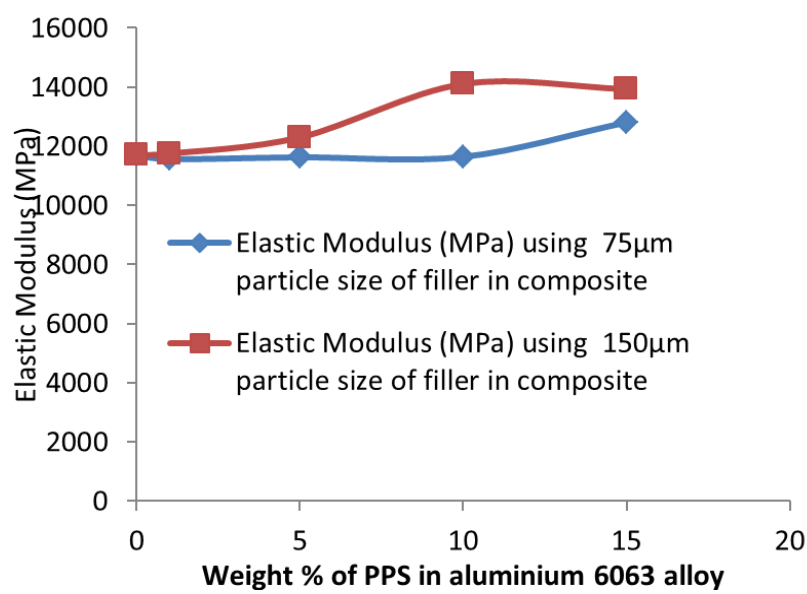

Figure 11: Elastic moduli of AA6063 alloy and PPSAIMMCS

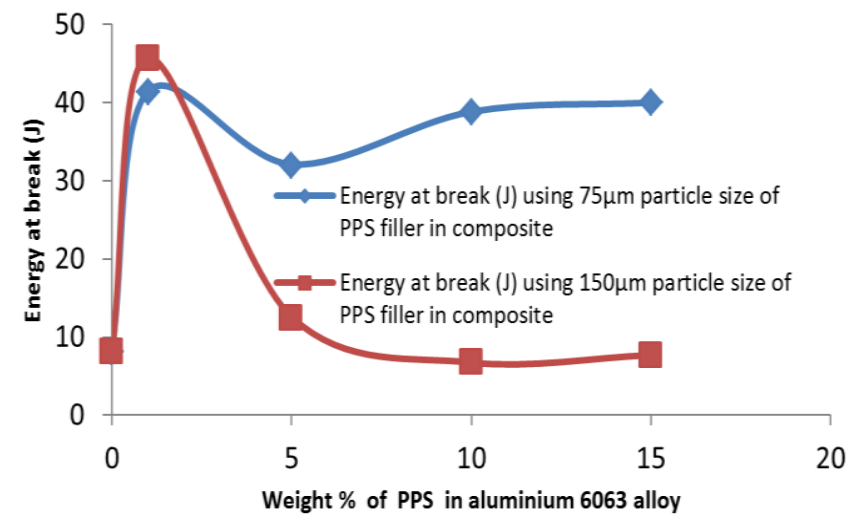

Figure 13: Energies at break of AA6063 alloy and PPS-AIMMCS

obtained depend on the PPS particle size and weight fraction in AA6063 alloy. The composites are cheaper than aluminuim matrix reinforced with carbide, oxide and boride fillers. The composites can be used in areas where lighter weight and higher strength are required within the aerospace, automotive and electronic industries such as cylinder liners in engines, aluminuim calipers and power electronic modules.

\section{REFERENCES}

[1] Babalola, P., Inegbenegbor, A., Bolu, C. and Inegbenegbor, A. "The Development of MolecularBased Materials for Electrical and Electronic Applications", The Journal of The Minerals, Metals and Materials Society, Vol.67, Number 4, 2015, pp 830-833, doi:10.1007/s11837-015-1355-2.

[2] Surapa, M. K. "Aluminium Matrix Composites: Challenges and Opportunities", $S^{-}$adhan $^{-}$, Vol.28, Numbers 1\&2, 2003, pp 319-334.

[3] Gladston, J. A., Sheriff, N. M., Dinaharan, I. and Selvam, J. D. "Production and Characterization of Rich Husk Ash Particulate Reinforced AA6061 Aluminum Alloy Composites by Compocasting", Transaction of the Nonferrous Society of China, Vol. 25, 2015, pp 683-691.

Vol. 36, No. 2, April 2017 
[4] Saravanan, C., Subramanian, K., Krishnan, V. A. and Narayanan, R. S. "Effect of Particulate Reinforced Aluminium Metal Matrix Composite -A Review", Mechanics and Mechanical Engineering, Vol.19, Number 1, 2015, pp 23-30.

[5] Singla, M., Dwivedi, D. D., Singh, L. and Chawla, V. "Development of Aluminium Based Silicon Carbide Particulate Metal Matrix Composite", Journal of Minerals and Materials Characterization \& Engineering, Vol. 8, Number 6, 2009, pp 455-467.

[6] Kuma, G. B., Rao, C. S., Selvaraj, N. and Bhagyashekar, M. S. "Studies on Al6061-SiC and Al7075-Al203 Metal Matrix Composites", Journal of Minerals and Materials Characterization and Engineering, Vol. 9, Number 1, 2010 pp 43-55.

[7] Mark, O. M., Adams, R., Fennessy, K. and Hay, R. A. "Aluminum Silicon Carbide (AlSiC) for Advanced Microelectronic Packages", Ceramics Process Systems Corp, IMAPS May 1998 Boston Meeting, 1999, pp 1-6.

[8] Agunsoye, J., Talabi, S., Bello, S. and Awe, I. "The Effects of Cocos Nucifera (Coconut Shell) on the Mechanical and Tribological Properties of Recycled Waste Aluminium Can Composites", Tribology in Industry, Vol. 36, Number 2, 2014, pp 155-162.

[9] Saravanan, S. and Senthilkumar, M. "Mechanical Behavior of Aluminum (AlSi10Mg)-RHA Composite", International Journal of Engineering and Technology, Vol. 5, Number 6, 2014, pp 48344840.

[10] Usman, A., Raji, A., Hassan, M. and Waziri, N. "A Comparative Study on the Properties of Al-7\%SiRice Husk Ash and Al-7\%Si-Bagasse Ash Composites Produced by Stir Casting", The International Journal of Engineering and Science, Vol. 3, Number 8, 2014, pp 1-7.

[11] Anilkumar, H., Hebbar, H. and Ravishankar, K. "Mechanical Properties of Fly Ash Reinforced Aluminium Alloy (Al6061) Composites", International Journal of Mechanical and Materials Engineering, Vol. 6, Number 1, 2011, pp 41-45.

[12] Ofem, M. I and Umar, M; Effect of Filler Content on the Mechanical Properties of Periwikle Shell
Reinforced CNSL Resin Composites, ARPN Journal of Engineering and Applied Sciences, 7(2), 212-215, 2012.

[13] Ofem, M. I., Abam, F. I. and Ugot, I. U. "Mechanical properties of Hybrid Periwinkle and Rice Husk Filled CNSL Composite", International Journal of Nano and Material Sciences, Vol. 1, Number 2, 2012, pp 74-80.

[14] Njoku, R., Okon, A. and Ikpaki, T. "Effects of Variation of Particle Size and Weight Fraction on the Tensile Strength and Modulus of Periwinkle Shell Reinforced Polyester Composite", Nigerian Journal of Technology, Volume 30, Number 2, 2011 pp 87-93.

[15] Onyechi, P. C., Asiegbu, K. O., Igwegbe, C. A. and Nwosu, M. C. "Effect of Volume Fraction on the Mechanical Properties of Periwinkle Shell Reinforced Polyester Composite (PRPC)", American Journal of Mechanical Engineering and Automation, Vol. 2, Number 1, 2015, pp 1-15.

[16] Yakubu, A. S., Amaren, S. and Yawas, D. S. "Evaluation of The Wear and Thermal Properties of Asbestos Free Brake Pad Using Periwinkles Shell Particles", Usak University Journal of Material Sciences, Volume 1, 2013, pp 1999-108.

[17] Yawas, D., Aku, S. and Amaren, S. "Morphology and Properties of Periwinkle Shell Asbestos-Free Brake Pad", Journal of King Saud University - Engineering Sciences, Volume 28, 2016, pp 103-109.

[18] Alaneme, K. and Bodunrin, M. "Mechanical Behaviour Of Alumina Reinforced AA6063 Metal Matrix Composites Developed by Two-Step Casting Process" ACTA TECHNICA CORVINIENSIS-Bulletin of Engineering, Volume 6, Number 3, 2013, pp 105110.

[19] ASTM E8M. "Standard Test Method for Tension of Metallic Materials (Metric) in Annua Book of ASTM Standards". Philadelphia: American Society of Testing and Materials, 1991.

[20] Kato, M. "Hall-Petch Relationship and Dislocation Model for Deformation of Ultrafine-Grained and Nanocrystalline Metals", Materials Transactions, Volume 55, Number 1, 2014, pp 19-24. 